\title{
Research Article \\ Determining the Optimum Tilt Angle and Orientation for Solar Energy Collection Based on Measured Solar Radiance Data
}

\author{
Danny H. W. Li and Tony N. T. Lam \\ Building Energy Research Group, Department of Building and Construction, City University of Hong Kong, \\ Tat Chee Avenue, Kowloon, Hong Kong
}

Received 28 May 2007; Accepted 20 September 2007

Recommended by Roel Van De Krol

A prior requirement to the design of any solar-based conversion systems is the knowledge of optimum orientation and tilt surface at which peak solar energy can be collected. In many parts of the world, however, the solar radiation data for the surfaces of interest are not always available. This paper presents a numerical approach to calculate the solar radiation on sloped planes by integrating the measured sky radiance distributions. The annual total solar yield at different sloped surfaces facing various orientations and monthly solar radiations at the optimal tilt surface and three vertical planes facing east, south, and west were determined. The energy outputs and efficiencies were simulated using a computer package. The environmental benefits in terms of greenhouse gases reductions and cost implications were also considered. The findings provide technical information for engineers to design and evaluate photovoltaic (PV) systems which could contribute to the environmental, energy, and economic aspects.

Copyright (C) 2007 D. H. W. Li and T. N. T. Lam. This is an open access article distributed under the Creative Commons Attribution License, which permits unrestricted use, distribution, and reproduction in any medium, provided the original work is properly cited.

\section{INTRODUCTION}

With rapid economic growth and improvement in living standards, there has been a marked increase in energy use for many developed and developing countries [1]. Hong Kong has no indigenous fuels and most of the imported energy products are fossil fuels which are mainly for electricity generation. There are many immediate adverse effects on the environment such as large amount of greenhouse gases and pollutants emissions from the burning of fossil fuels [2]. Electricity is high-grade energy which is less efficient than other commonly used fuels. Generally, three units of primary energy inputs are needed to produce one unit of electricity output, with two units being wasted as heat. It implies that one unit of electricity saved means about three units of nonrenewable fossil fuel conserved together with the likely pollutants and the greenhouse gases reductions. Renewable energy can play an essential role in meeting the ultimate goal of replacing certain parts of fossil fuels. One of the promising applications of renewable energy technology is the installation of photovoltaic (PV) systems that generate power without emitting pollutants and requiring no fuel. A local study on renewable energy reported that PV technologies are po- tentially suitable for wide scale applications in Hong Kong [3].

Conventionally, stand-alone PV systems have been used in rural and remote areas where normal electricity supply may not be readily accessible. In modern urban cities with many compactly built high-rise blocks, the concept of building integrated photovoltaics (BIPV) would be an appropriate alternative form to receive solar energy [4]. In designing the optimal tilt angle and orientation of a fixed solar panel for maximising its energy collection is to acquire the maximum solar radiation availability at the required location, a number of studies have been conducted by various researchers to determine the optimum location for solar radiation collection using different empirical models [5-8]. However, solar radiation varies with geographic latitude, season, and time of a day due to the various sun positions under the unpredictable weather conditions. Systematic long-term data measurements are regarded as the most effective and accurate method of setting up the solar radiation database. In many parts of the world, the basic solar data for the surfaces of interest are not always readily obtainable. It is also impracticable to measure the solar radiation for every tilt angle to deduce the peak value. Traditionally, solar radiation on an inclined surface is modelled using horizontal data [9]. 
Alternatively, the solar radiation of an inclined plane can be computed by integrating the radiance distribution of the sky "seen" by the plane [10]. Recently, a sky scanner has been installed at the City University of Hong Kong to record the solar radiances of the whole sky. This study presents the work on the prediction of solar radiation for various inclined angles and orientations using the measured sky radiances. The likely electricity generations, the environmental benefits, and cost implications for solar panels installed at the optimum tilt angles and orientations are computed and analyzed. The characteristics of the findings and design implications are discussed.

\section{SKY RADIANCE MEASUREMENTS AND DATA QUALITY CONTROLS}

A measuring station was established at the City University of Hong Kong in 1991. The instruments were installed on the roof-top in a position relatively free from external obstructions and accessible for general inspection and maintenance. Initially, only measurements of global and diffuse solar radiation on a horizontal plane were made. In 1996, the measurement was extended to record vertical global solar radiation on four cardinal surfaces facing the north, east, south, and west [11]. Totally, six pyranometers with an expected error of 3\% manufactured and calibrated by Kipp and Zonen, the Netherlands, were used for the solar radiation data measurements. The radiation data were captured simultaneously twice per second and averaged over 10-minute intervals. The specifications for high-quality solar radiation measurements can be found from the guide published by the World Meteorological Organization [12].

In 1999, a sky scanner (EKO MS 300 LR) was installed at the City University of Hong Kong to record the sky radiance at 145 points (shown in Figure 1) of the sky by scanning the whole skydome. The scanner was manufactured and calibrated by the EKO Company of Japan. The errors for radiance sensor are $0.5 \%$ for linearity and $0.1 \% /{ }^{\circ} \mathrm{C}$ for temperature coefficient. The full view angle of the scanner is $11^{\circ}$ with an accuracy of pointing of $0.2^{\circ}$ - that allows each sky patch to be treated as a point source with negligible error [13]. The measurement would lead to uncovered regions of the sky and it gives sky coverage of approximately $68 \%$. The sky grid pattern shown in Figure 1 was suggested by Tregenza and Sharples [14] such that the whole skydome can be considered for subsequent analysis. The important parts of the sky scanner are housed in a weatherproof casing allowing continuous outdoor operation. Output data from the scanner are recorded on a microcomputer located inside the laboratory space on the top floor. To safeguard the sensor, the scanner does not record radiance data of greater than $210 \mathrm{~W} / \mathrm{m}^{2} \mathrm{sr}$ $\left(\approx 35 \mathrm{kcd} / \mathrm{m}^{2}\right)$ by using an automatic shutter. Each scanning time is about 4 minutes and measurements are taken every 10 minutes. Data collection starts before sunrise and finishes after sunset. All measurements are recorded in terms of true solar-time. This facilitates the computations involving solar altitude for the extraterrestrial radiation on unit horizontal surface and the subsequent comparison of data for different locations.
It is essential to ensure that the measured solar radiation and sky radiance data for analysis are reliable. To eliminate spurious data and inaccurate measurements, some qualitycontrol tests were conducted as follows:

(i) applying a shadow-ring correction to the measured horizontal diffuse data according to the method described by LeBaron et al. [15] (The shadow ring would block certain amount of the sky-diffuse components);

(ii) rejecting the sky radiance data centered within $11^{\circ}$ of the sun's position [16] (to eliminate the direct-beam components of very large values);

(iii) rejecting all diffuse data greater than the corresponding global values (diffuse data should never be greater than the corresponding global values);

(iv) rejecting all global data greater than the corresponding extraterrestrial solar components (global data should never be greater than the corresponding extraterrestrial solar components);

(v) rejecting all data with a solar altitude, $\alpha$, less than $5^{\circ}$ (at very low solar altitudes, data are often unreliable due mainly to shading and reflections from nearby objects and the cosine effect of the sensors);

(vi) rejecting all data when horizontal global radiation data less than $20 \mathrm{Wh} / \mathrm{m}^{2}$ [16] (small horizontal global components always appear at very low solar altitudes);

(vii) rejecting all data when the direct normal values (i.e., (global-diffuse)/ $\sin \alpha$ ) exceeded the corresponding extraterrestrial solar components (direct normal values should never be greater than the corresponding extraterrestrial solar values);

(viii) rejecting all diffuse data greater than half of the corresponding extraterrestrial solar components (because the shadow-ring was not properly adjusted);

(ix) rejecting all sky radiance data when the differences between the measured diffuse horizontal data and the corresponding integrated diffuse horizontal components from the scanner were greater than 30\% [16] (to ensure consistency between the measured diffuse components and the corresponding sky radiances during the scan); around $2.5 \%$ sets of data were rejected according to this criterion using data collected in 2004.

By applying the quality-control tests, horizontal direct radiation data were obtained by subtracting the corrected diffuse components from the corresponding global values.

\section{SKY RADIANCE MODEL}

For stand-alone PV applications, it is necessary to know the incident solar radiation on an inclined surface $[17,18]$. It is also desirable to have solar radiation data on vertical surfaces for BIPV system designs [19]. The incident solar radiation on a slope plane with an inclination angle $\beta\left(I_{\beta G}\right)$ can be evaluated as the sum of direct-beam, sky-diffuse, and groundreflected components. It can be given as

$$
I_{\beta G}=I_{\beta B}+I_{\beta D}+I_{\beta R}
$$




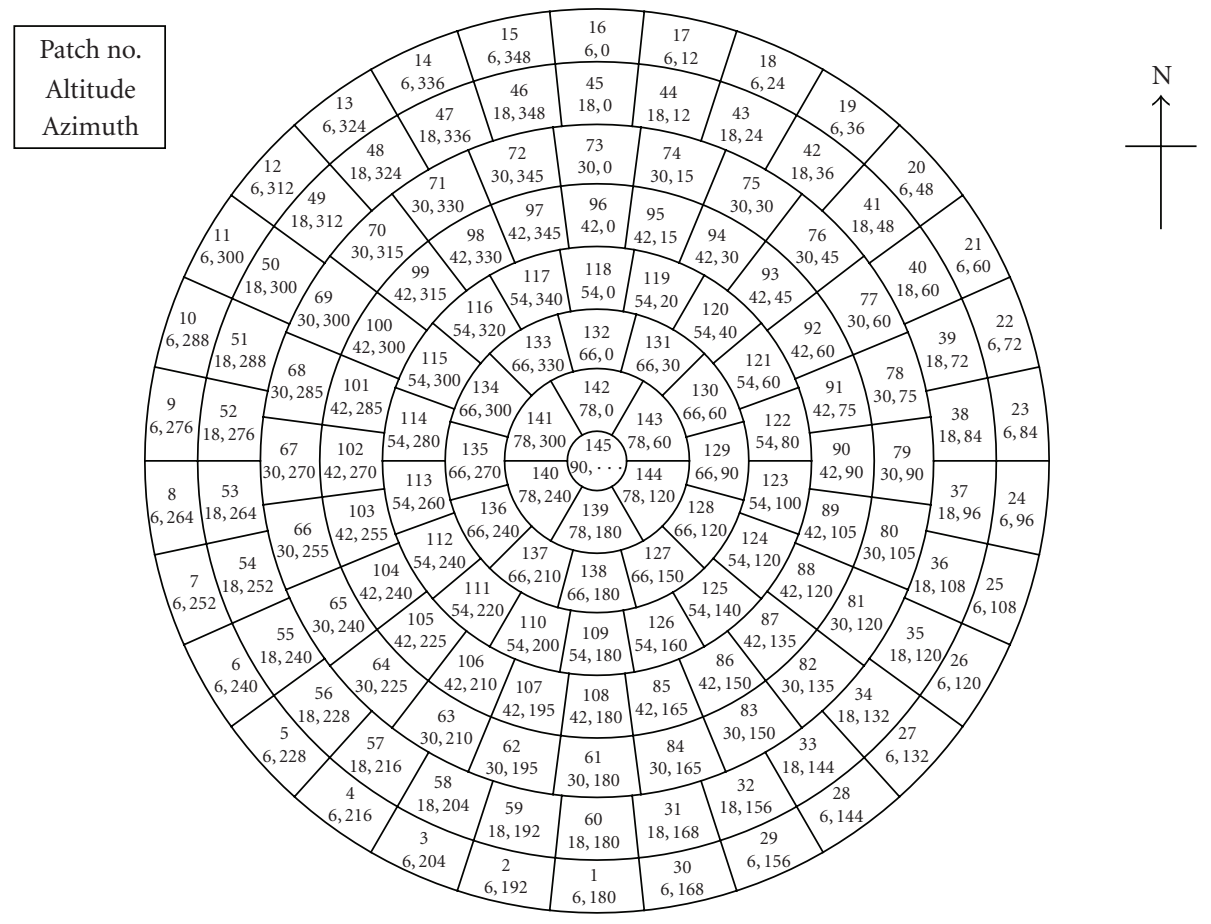

FIgURE 1: The measurement points for the sky scanner.

where $I_{\beta B}$ is direct-beam radiation on a plane $\left(\mathrm{Wh} / \mathrm{m}^{2}\right) ; I_{\beta D}$ is sky-diffuse radiation on a plane $\left(\mathrm{Wh} / \mathrm{m}^{2}\right) ; I_{\beta R}$ is groundreflected radiation on a plane $\left(\mathrm{Wh} / \mathrm{m}^{2}\right)$.

By giving the position of the sun and orientation of the plane, it is quite straightforward to calculate the direct-beam radiation on any tilt surface. For estimating the groundreflected radiation, it is assumed that the inclined surface receives the global radiation reflected isotropically from the ground. Figure 2 illustrates the solar geometry. Mathematically, $I_{\beta B}$ and $I_{\beta R}$ can be expressed as follows:

$$
\begin{gathered}
I_{\beta B}=\left(\frac{I_{h B}}{\sin \alpha}\right)\left(\sin \alpha \cos \beta+\cos \alpha \sin \beta \cos \left|\gamma-\gamma_{n}\right|\right), \\
I_{\beta R}=\frac{\rho I_{h G}(1-\cos \beta)}{2},
\end{gathered}
$$

where $I_{h B}$ is horizontal direct beam radiation $\left(\mathrm{Wh} / \mathrm{m}^{2}\right) ; I_{h G}$ is horizontal global radiation $\left(\mathrm{Wh} / \mathrm{m}^{2}\right) ; \alpha$ is solar altitude (rad); $\gamma$ is solar azimuth ( $\mathrm{rad}) ; \gamma_{n}$ is azimuth angle of the normal of the surface ( $\mathrm{rad}$ ), for example, $\gamma_{n}=\pi / 2$ for surface facing east.

The critical issue is the determining of the sky-diffuse component. Owing to the strong forward scattering effect of aerosols, sky-diffuse radiation should be treated as anisotropic. Multiple scattering due to atmospheric aerosols, ozone and nitrogen oxide complicate the evaluation of the hemispheric sky-diffuse components [20]. The sky-diffuse radiation is substantially affected by the radiance levels and sky distributions in the direction viewed from the surface. An appropriate approach of computing the sky-diffuse radiation on an inclined surface would be to integrate the radiance over

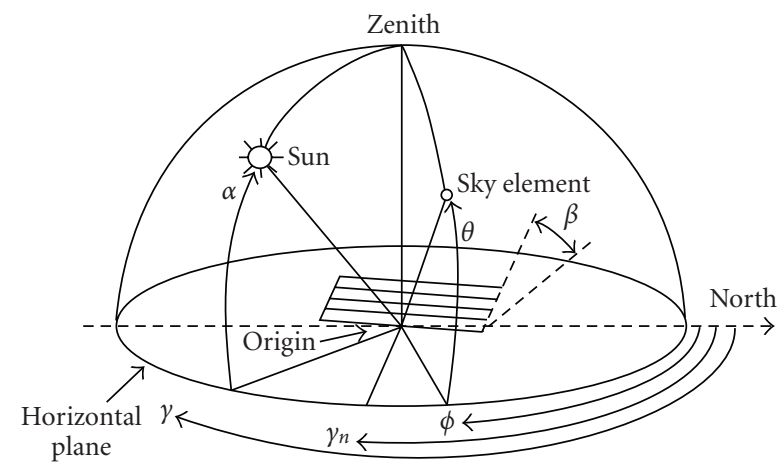

Figure 2: Definition of solar and sky angles.

the skydome visible to the surface. The radiation on a plane, $\delta I$, resulting from a small patch of sky is given by

$$
\begin{aligned}
\delta I & =R_{\theta \phi} \cos \sigma \delta \omega, \\
\delta \omega & =\cos \theta \delta \theta \delta \phi, \\
\cos \sigma & =\sin \theta \cos \beta+\cos \theta \sin \beta \cos \phi,
\end{aligned}
$$

where $R_{\theta \phi}$ is radiance of a sky element at altitude $\theta$ and azimuth $\phi\left(\mathrm{W} / \mathrm{m}^{2} \mathrm{sr}\right) ; \omega$ is solid angle (sr); $\sigma$ is angle between the sky element and the line normal to the surface (rad).

The sky geometry is also shown in Figure 2. By using double integrals, $I_{\beta D}$ can be determined as

$$
I_{\beta D}=\int_{\theta_{1}}^{\theta_{2}} \int_{\phi_{1}}^{\phi_{2}} R_{\theta \phi} \cos \theta(\sin \theta \cos \beta+\cos \theta \sin \beta \cos \phi) \mathrm{d} \phi \mathrm{d} \theta .
$$


The ranges for $\theta\left(\theta_{1}\right.$ and $\left.\theta_{2}\right)$ and $\phi\left(\phi_{1}, \phi_{2}\right)$ are from 0 to $\pi / 2$ and from 0 to $2 \pi$, respectively, depending on the sky elements' positions "seen" by the inclined surface.

For all but the simplest cases (e.g., sky-diffuse radiation from a uniform or an isotropic overcast sky on an unobstructed surface), it is not possible to compute the above double integrals analytically. If the sky diffuse component was divided into $n$ angular zones, then for numerical computation, (5) can be obtained numerically as

$$
I_{\beta D}=\sum_{i=1}^{n} R_{i} \omega_{i} \cos \sigma_{i}
$$

The sky-diffuse radiation at a particular point can be calculated by the sum of $n$ products of $R, \omega$, and $\cos \sigma$ for each sky patch. As the scanning pattern divided the whole skydome into 145 points, the solar radiation for any inclined surfaces facing various orientations can be determined based on (6) using measured solar radiance data. It should be pointed out that there are several causes affecting the accuracy of the measured sky radiance data. Firstly, the division of the sky into 145 circular angular patches can avoid any double counting, but it may lead to uncovered regions of the sky. Secondly, the measured data were based on discrete results rather than continuous analytical functions. Sky radiances between adjoining measurement points may have varied significantly. Thirdly, the scanning time was about 4 minutes and the measurement interval was 10 minutes. Substantial variations in sky radiance may have occurred between each record. Also, for "out of range" measurements (points close to the solar position under nonovercast skies), an estimation of the sky radiance was made from a simple average of the radiance at nearby points, and such conversion could introduce data distortion [21]. Previous findings, however, showed that the numerical method can provide an acceptable alternative to determine the amount of solar radiation on a horizontal surface and vertical planes facing the four cardinal orientations when sky radiance data are available [10].

\section{RESULT ANALYSIS}

Solar radiation and sky radiance data recorded during the 12month period from January to December 2004 were gathered for the study. It is inevitable that there are some short periods of missing data for various reasons, including instrumentation malfunction and power failure. Considerable efforts were made to obtain a continuous record of data and in all about 21200 sets of 10 -minute readings were recorded simultaneously from the above measurements.

\subsection{Annual solar yield}

The amount of power generated by the PV system is strongly affected by the amount of solar radiation falling on the PV panel. Based on (2), the annual beam radiation falling upon surfaces of various tilt angles and orientations were determined accordingly and Figure 3 displays the results. It can be seen that the annual beam radiation at different tilt angles and orientation varies from less than $100 \mathrm{kWh} / \mathrm{m}^{2}$ to over

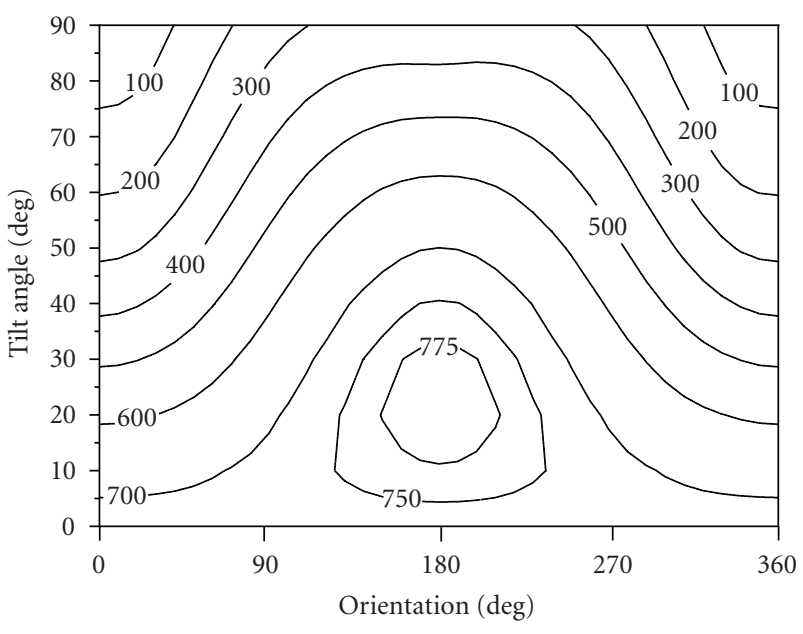

FIgURE 3: Annual beam solar radiation $\left(\mathrm{kWh} / \mathrm{m}^{2}\right)$ for various tilt angles and orientations.

$775 \mathrm{kWh} / \mathrm{m}^{2}$. Generally, the solar radiation decreases gradually with an increasing tilt angle from horizontal to vertical surfaces. The peak value of more than $775 \mathrm{kWh} / \mathrm{m}^{2}$ can be found at the inclined angles between $10^{\circ}$ and $30^{\circ}$ with the azimuth angles from $150^{\circ}$ to $210^{\circ}$. Figure 3 also indicates that the annual direct component is quite symmetrical with respect to south $\left(180^{\circ}\right)$. Owing to the sun path in Hong Kong, south-facing planes can "see" the sun for most of the daytime around a year, resulting in the largest amount of solar radiation received among all cardinal surfaces. As the sun can be visible in the morning for east-facing surfaces and in the afternoon for west-facing surfaces, the solar radiations obtained at the planes facing these two orientations are very close to each other. With the shortest period facing the direct sun, the solar radiation falling on the north-facing vertical plane is the lowest.

The sky-diffuse radiation of an inclined surface was estimated by integrating the radiance distribution of the sky visible to the surface. To obtain reliable diffuse component, the scanned radiance of each sky patch over the whole skydome was multiplied by a normalization ratio $\left(\mathrm{NR}_{\mathrm{scan}}\right) \mathrm{using}$ the measured horizontal diffuse component $I_{\mathrm{HD}}$ as

$$
\mathrm{NR}_{\mathrm{scan}}=\frac{I_{\mathrm{HD}}}{\sum_{i=1}^{145} R_{i} \omega_{i} \cos \sigma_{i}} .
$$

By putting a common ground reflectivity of 0.2 (i.e., $\rho$ $=0.2$ ) [22], the diffuse and reflected components at various sloped planes and orientations were calculated and are presented in Figure 4. The annual radiation ranges from just below $450 \mathrm{kWh} / \mathrm{m}^{2}$ to slightly over $800 \mathrm{kWh} / \mathrm{m}^{2}$. Similar pattern as that shown in Figure 3 is observed but with larger values particular in high tilt angles (i.e., vertical surfaces). In general, the variations are less than those in direct component. The whole sky is "seen" by the horizontal surface but the peak solar radiation was not recorded at this plane. It indicates that the annual reflected radiation on an inclined surface of a small tilt angle would be more than the sky-diffuse component at low sky elevation. 


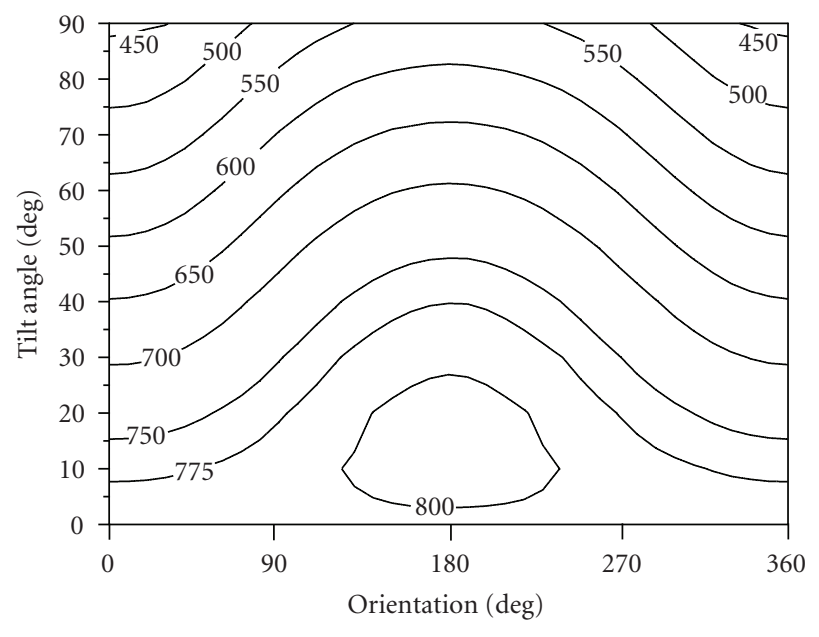

FIgURE 4: Annual sky-diffuse and reflected solar radiation $\left(\mathrm{kWh} / \mathrm{m}^{2}\right)$ for various tilt angles and orientations.

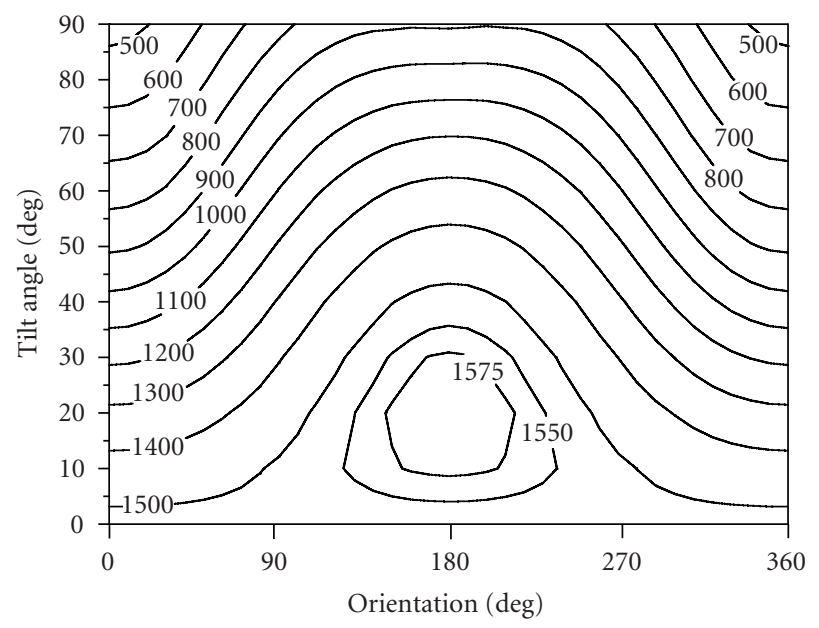

FIGURE 5: Annual total solar yield $\left(\mathrm{kWh} / \mathrm{m}^{2}\right)$ for various tilt angles and orientations.

Accordingly, the annual total solar yield was determined and is shown in Figure 5. The peak value is $1575 \mathrm{kWh} / \mathrm{m}^{2}$ which is quite good for active solar applications and more than a number of places [23]. To further examine the optimum inclination, the annual solar yields for sloped angles between $0^{\circ}$ and $30^{\circ}$ oriented due south (i.e., azimuth angle $=180^{\circ}$ ) were estimated and Figure 6 shows the findings. It can be seen that the annual solar radiation on a horizontal surface is around $1528 \mathrm{kWh} / \mathrm{m}^{2}$. The solar radiation rises with the tilt angle up to about $20^{\circ}$ at which the maximum annual solar yield of $1598.4 \mathrm{kWh} / \mathrm{m}^{2}$ occurs. When the tilt angle is beyond $20^{\circ}$, the annual solar yield falls slightly with increasing tilt angles. As the latitude of Hong Kong is $22.3^{\circ} \mathrm{N}$, the finding supports the argument that the optimal tilt angle for solar energy collection would be very close to the angle equivalent to the latitude of the location $[5,24]$.

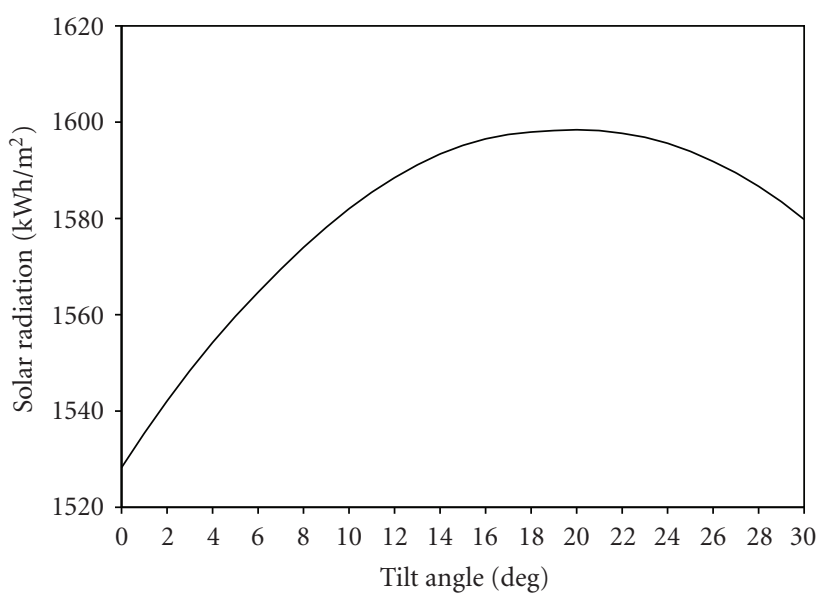

FIGURE 6: Solar radiation against tilt angles for the south-facing surface.

\subsection{Monthly solar radiation}

Proper PV system design requires accurate solar resource information. It would be cost effective for PV systems when the utility load and solar resources profiles are well matched [25]. This is particularly beneficial to subtropical Hong Kong where air-conditioning loads for commercial buildings during the hot summer months accounts for over $50 \%$ of the total electricity consumption. It would be useful to have the solar radiation data in individual months. The monthly solar radiation for the inclined surface at the optimal angle (i.e., inclined angle of $20^{\circ}$ due south), and the three vertical surfaces facing east, south, and west were determined and are presented in Figure 7. Being installed at the optimal angle, the inclined plane always receives the largest solar radiation in each month, ranging from $91.2 \mathrm{kWh} / \mathrm{m}^{2}$ in March to $170.9 \mathrm{kWh} / \mathrm{m}^{2}$ in October. For vertical surfaces, the monthly values vary from $40.3 \mathrm{kWh} / \mathrm{m}^{2}$ in March for the east-facing plane to over $128 \mathrm{kWh} / \mathrm{m}^{2}$ in December for the south-facing plane. In general, the monthly profiles of solar radiation values for the east-facing and west-facing surfaces are quite similar, with the latter being slightly larger. As the sun is in the south of low solar altitude, the south-facing vertical surface receives quite large solar radiation between October and December. The low solar radiation data obtained from January to April for all surfaces are mainly due to the short day-length in winter and the unstable weather conditions in spring. Similar findings were reported in our previous studies [26]. The annual solar radiation obtained for east-, south-, and west-facing vertical surfaces are $770 \mathrm{kWh} / \mathrm{m}^{2}$, $888 \mathrm{kWh} / \mathrm{m}^{2}$, and $776 \mathrm{kWh} / \mathrm{m}^{2}$, respectively. The results indicate that the south-facing facades are appropriate for BIPV applications but the solar resources for this orientation are not well-matched with the building load schedules.

\subsection{Energy output}

In designing and evaluating PV systems, it is necessary to know the output energy performances. It has been reported in the literature that the performance of a PV system is a 


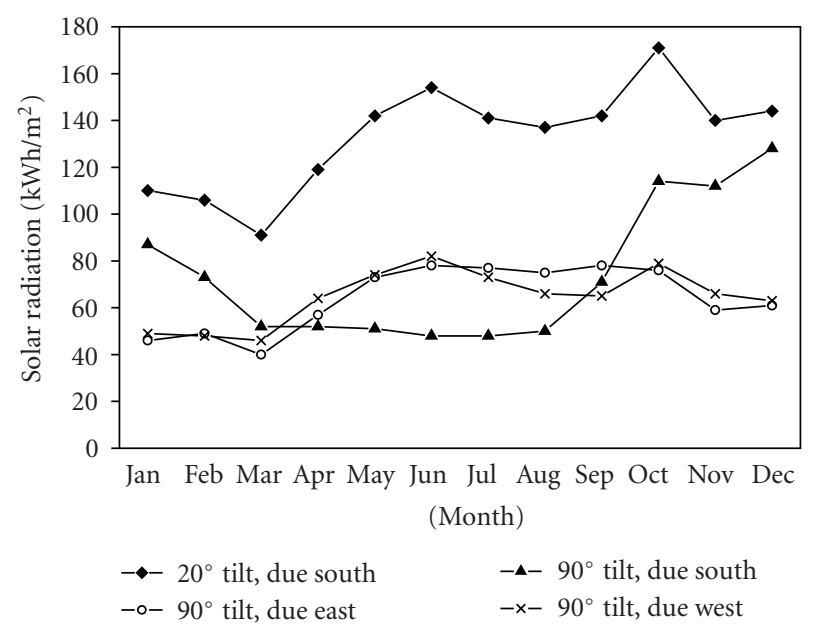

FIGURE 7: Monthly solar radiation on inclined surfaces.

function of solar radiation received, ambient temperature and air mass [27]. The energy output was modeled using a computer program called TRNSYS with the "integrated" solar radiation and ambient temperature obtained in 2004. TRNSYS is a transient simulation program which was designed to solve complex energy system issues by breaking the problem down into a series of smaller components [28, 29]. The mathematical models for the subsystem components are given in terms of their ordinary differential or algebraic equations. The component programs can be modified and new components may be added without recompiling the program. The PV panels used for simulation were Kyocera modules made up of multicrystalline silicon cells. Table 1 summarizes the input data according to the manufacturer's catalogue [17]. Assuming that the PV panels were installed on the rooftop facing south at an inclination angle of $20^{\circ}$ without any sky obstruction to obtain maximum annual solar radiation in Hong Kong. Again, the common ground reflectivity of 0.2 (humid tropical localities) for the foreground faced by the PV panels was used [22]. The solar radiation, ambient temperature, and angle of incidence are essential data to the simulation of the energy generated from the PV systems. The ambient temperature data were obtained from the Hong Kong Observatory (HKO) which is the local meteorological station measuring a large variety of weather data for many years. The air mass data was computed using simple solar geometry. The electricity generated by the PV system was supposed to be injected into the grid for use and the battery with associated accessories was not required. Accordingly, the monthly PV energy generated and the corresponding efficiency defined as the ratio of the output energy produced to the solar radiation incident on the PV panels were determined and Figure 8 presents the findings. The simulated monthly output energy ranges from $8.4 \mathrm{kWh} / \mathrm{m}^{2}$ in March to $15.4 \mathrm{kWh} / \mathrm{m}^{2}$ in October. The small energy generated in March is mainly due to the lowest monthly solar radiation received. The stable weather conditions together with long sunshine hours in autumn contribute to the highest energy generated in October. The efficiency does not differ a great
TABLE 1: Input parameters of PV array for energy simulation.

\begin{tabular}{lc}
\hline Parameter & Input value \\
\hline Module short-circuit current at reference conditions $(\mathrm{A})$ & 3.37 \\
Module open-circuit voltage at reference conditions $(\mathrm{V})$ & 21.5 \\
Module voltage at maximum power point $(\mathrm{V})$ & 16.9 \\
Module current at maximum power point $(\mathrm{A})$ & 3.55 \\
Temperature coefficient of short-circuit current $(\mathrm{A} / \mathrm{K})$ & 0.00304 \\
Temperature coefficient of open-circuit voltage $(\mathrm{V} / \mathrm{K})$ & -0.0824 \\
Number of cells wired in series in module & 36 \\
Number of modules in series in array & 4 \\
Number of modules in parallel in array & 1 \\
Individual module area ( $\left.{ }^{2}\right)$ & 0.5 \\
Module series resistance $(\Omega)$ & 0.4 \\
Load voltage $(\mathrm{V})$ & 12 \\
Array slope (degrees) & 20
\end{tabular}

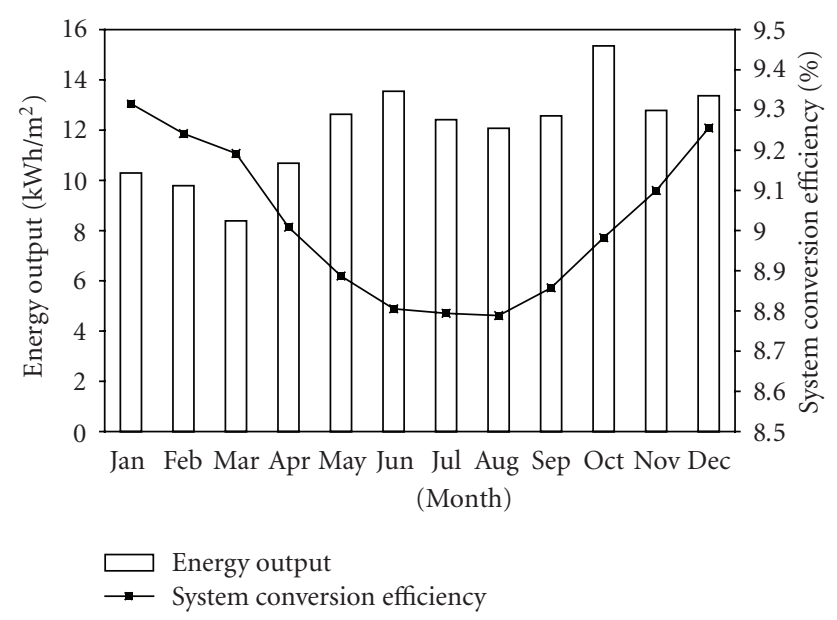

FIGURE 8: Monthly PV energy output and system conversion efficiency in 2004.

deal, ranging from $8.8 \%$ to just above $9.3 \%$. With low temperatures in winter, the highest efficiencies appear in December, January and February [30]. The simulated total energy output is $144 \mathrm{kWh} / \mathrm{m}^{2}$ in year 2004 representing an average annual efficiency of $9 \%$.

The annual total energy outputs were also simulated on a combination of cardinal orientations and tilt in order to have a general picture of design implications for various PV systems (i.e., stand-alone and BIPV). The selected aspects were east, south and west. For each of the aspects, the tilt angles were chosen from $0^{\circ}$ to $90^{\circ}$ in an interval of $10^{\circ}$. The results are plotted in Figure 9. As computed in previous section, the optimal inclined angle is of around $20^{\circ}$ due south. Beyond the optimal sloped angle, the energy outputs drop gradually. Generally, the energy output decreases with increasing tilt angles. For a given tilt angle, PV panels facing south always generate the largest energy outputs. The annual output energy for the PV panels installed on a horizontal and 


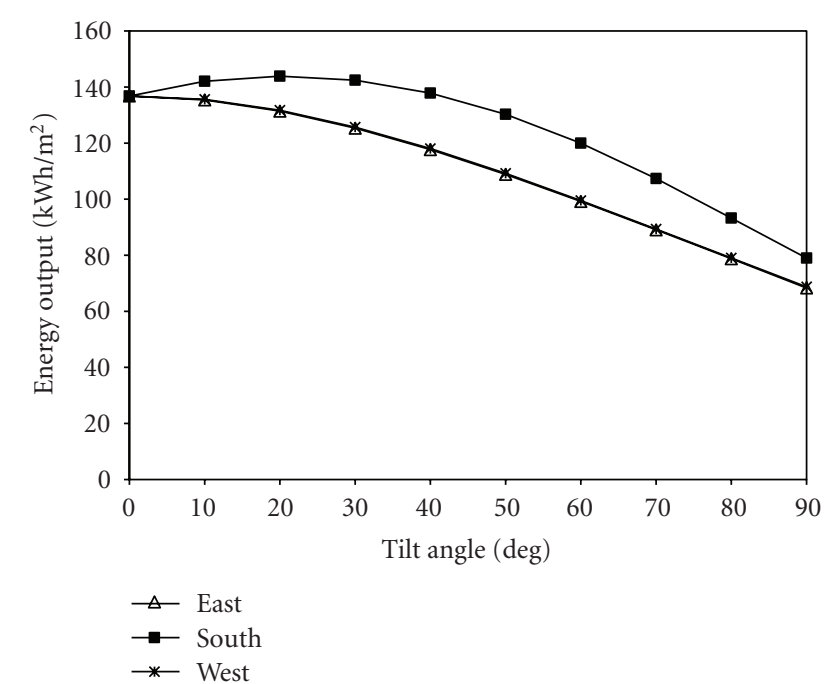

FIgURE 9: Annual PV energy output for various tilt angles and orientations.

TABle 2: Electricity generation and gas emissions produced by China Light and Power Company, Hong Kong, in 2004.

\begin{tabular}{lc}
\hline Electricity generated & $23809 \mathrm{GWh}$ \\
$\mathrm{CO}_{2}$ & $16867 \times 10^{6} \mathrm{~kg}$ \\
$\mathrm{SO}_{2}$ & $51800 \times 10^{3} \mathrm{~kg}$ \\
$\mathrm{NO}_{x}$ & $28600 \times 10^{3} \mathrm{~kg}$ \\
Particulates & $2200 \times 10^{3} \mathrm{~kg}$ \\
\hline
\end{tabular}

the south-facing vertical planes are 137 and $79 \mathrm{kWh} / \mathrm{m}^{2}$, respectively. The energy output patterns for east- and westfacing vertical PV panels are almost identical of around $70 \mathrm{kWh} / \mathrm{m}^{2}$.

\subsection{Emission reduction and monetary payback}

The global environmental hazard posed by emissions from burning fossil fuel has become an additional driving force for the use of renewable and sustainable energy. Economical and environmental issues were often employed to evaluate the design of various solar-based conversion systems [31, 32]. In Hong Kong, electricity is largely generated from fossil fuels by two local power companies. Greenhouse gases and pollutants produced from electricity generation are considered one of the main causes of the local air pollution. Table 2 shows the electricity generations and gas emissions by one of the local power companies in 2004 [2]. The annual electricity produced by this power company was around $23800 \mathrm{GWh}$ and $\mathrm{CO}_{2}$ was the largest greenhouse gas product with the emission of over 16860 kton. For other pollutants, the quantity was far less than that of $\mathrm{CO}_{2}$, ranging from 2.2 kton for particulates to $51.8 \mathrm{kton}$ for $\mathrm{SO}_{2}$. The environmental benefits were also estimated based on the simulated results. The annual emissions of $\mathrm{CO}_{2}, \mathrm{SO}_{2}, \mathrm{NO}_{x}$, and particulates could be reduced, respectively, by $102,0.31,0.17$, and $0.013 \mathrm{~kg}$ per unit square meter if the PV panels were installed at the opti-

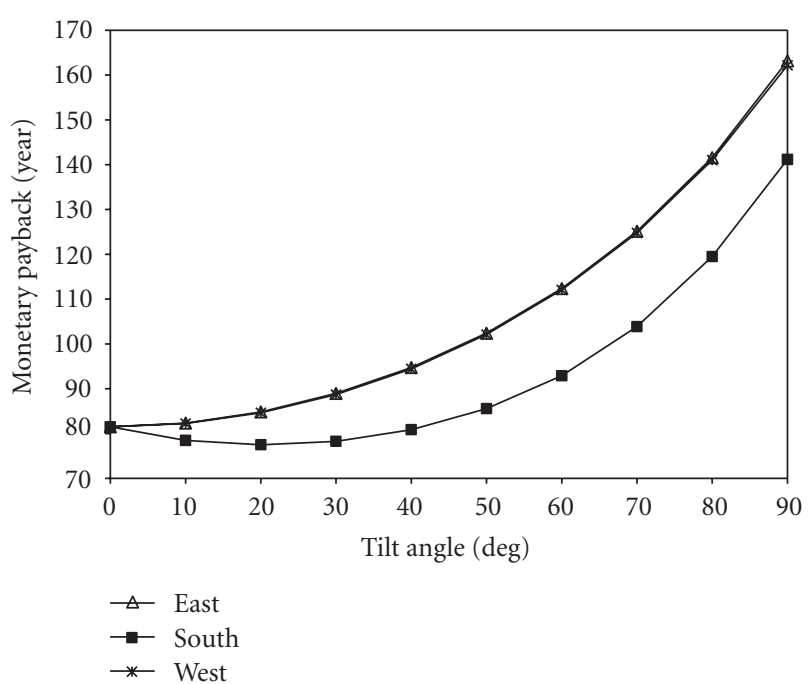

FIGURE 10: Monetary payback for various tilt angles and orientations.

mal angle to generate electricity. Generally, the environmental benefits from using renewable energy are significant.

The evaluation of the economical benefits contributed by the PV systems was determined in terms of the monetary payback. The budget including the multicrystalline silicon PV module and the supporting electrical installation was estimated by making reference to the capital costs of the recent project [17]. The budget of the multicrystalline silicon PV system installations was computed to be about $\mathrm{HK} \$ 10$ $860 / \mathrm{m}^{2}$ (US\$1 390/ $\mathrm{m}^{2}$ ). Using an average commercial electric tariff of $\$ 0.974(\approx$ US\$0.125) per kWh for Hong Kong and the simulated PV energy outputs, the annual savings in electricity fee were calculated. Figure 10 presents the monetary payback for the surfaces at various tilt angles and orientations. The monetary payback curves show inverse trends to the energy output lines as demonstrated in Figure 9. The payback year varies from 77.5 years for PV panels installed at the optimal angle (inclined angle of $20^{\circ}$ due south) to 163 years installed at east-facing vertical plane. The findings are in a par with the monocrystalline silicon PV system located in Edinburgh [32]. It should be pointed out that solar cells of mono-crystalline have better conversion efficiency than those made of multicrystalline silicon. This implies that the potential of applying PV systems in Hong Kong is not bad compared to the PV facility installed in Edinburgh. The inflation of electricity price was not considered in this study. As the energy price is forecasted to increase in the future, the monetary payback period would drop rapidly.

\section{CONCLUSIONS}

An approach of employing sky radiance model for determining an optimum tilt angle and orientation for maximizing annual solar yield was conducted. The whole year (2004) 10minute horizontal radiation and sky radiance data recorded in Hong Kong were used for the analysis. The incident solar radiation data on various inclined surfaces facing different 
orientations were calculated. The optimum tilt angle was found to be around $20^{\circ}$ due south, which would receive the annual solar yield over $1598 \mathrm{kWh} / \mathrm{m}^{2}$. The findings support that a solar collector with the tilt angle approximately equal to latitude of the place could receive maximum annual solar radiation. The monthly solar radiation data on various vertical surfaces were analyzed with the view to evaluate the applications of BIPV systems. South vertical surface was found to be the optimal vertical surface to receive peak annual solar radiation. The TRNSYS simulation tool was applied to investigate the operational performance of the multicrystalline silicon PV system installed at the optimum tilt angle and three vertical planes facing east, south and west. High efficiencies were resulted in winter months because of the low ambient temperature. The largest simulated energy output was found in October which may be due mainly to the stable weather conditions and long sunshine hours. For vertical surfaces, south-facing PV systems were computed to give the largest energy outputs among all orientations. The simulated PV energy outputs at east- and west-facing surfaces were almost identical. In environmental point of view, the annual emissions of $\mathrm{CO}_{2}, \mathrm{SO}_{2}, \mathrm{NO}_{x}$, and particulates could be reduced, respectively, by $102,0.31,0.17$, and $0.013 \mathrm{~kg}$ per unit square meter of a PV panel installed at the optimal angle to generate electricity in Hong Kong. In view of financial aspect, the shortest monetary payback of 77.5 years was estimated for the optimal angle (inclined angle of $20^{\circ}$ due south). Renewable energy is one of the best solutions to provide clean energy. The findings in this study are expected to give the design ideas for the architects and building engineers to apply PV technology.

\section{ACKNOWLEDGMENTS}

The work described in this paper was fully supported by a grant from the Research Grants Council of the Hong Kong Special Administrative Region, China, (Project no. 9041140 (CityU 116506)). T. N. T. Lam is supported by a City University of Hong Kong studentship.

\section{REFERENCES}

[1] H. Yoshino, "Current status of energy use and low GHG emission strategies for residential buildings in Japan and China," Journal of Harbin Institute of Technology, vol. 14, no. 1, pp. 15, 2007.

[2] China Light Power Group, "Social and environmental report," China Light and Power Holdings Limited, HKSAR, China, 2005.

[3] Electrical Mechanical Services Department, "Study on potential applications of renewable energy in Hong Kong, stage one: study report," Electrical and Mechanical Services Department, HKSAR, China, 2002.

[4] P. Clarke, A. Davidson, J. Kubie, and T. Muneer, "Two years of measured performance of a medium-sized building integrated photovoltaic facility at Napier University, Edinburgh," in Proceedings of the 3rd International Conference on Solar Radiation and Day Lighting (Solaris '07), vol. 1, pp. 382-386, New Delhi, India, February 2007.
[5] H. Gunerhan and A. Hepbasli, "Determination of the optimum tilt angle of solar collectors for building applications," Building and Environment, vol. 42, no. 2, pp. 779-783, 2007.

[6] K. K. Gopinathan, N. B. Maliehe, and M. I. Mpholo, "A study on the intercepted insolation as a function of slope and azimuth of the surface," Energy, vol. 32, no. 3, pp. 213-220, 2007.

[7] R. Tang and T. Wu, "Optimal tilt-angles for solar collectors used in China," Applied Energy, vol. 79, no. 3, pp. 239-248, 2004.

[8] S. Karatasou, M. Santamouris, and V. Gero, "On the calculation of solar utilizability for south oriented flat plate collectors tilted to an angle equal to the local latitude," Solar Energy, vol. 80, no. 12, pp. 1600-1610, 2006.

[9] R. Perez, P. Ineichen, R. Seals, J. Michalsky, and R. Stewart, "Modeling daylight availability and irradiance components from direct and global irradiance," Solar Energy, vol. 44, no. 5, pp. 271-289, 1990.

[10] D. H. W. Li and J. C. Lam, "Predicting solar irradiance on inclined surfaces using sky radiance data," Energy Conversion and Management, vol. 45, no. 11-12, pp. 1771-1783, 2004.

[11] D. H. W. Li and J. C. Lam, "Vertical solar radiation and daylight illuminance data for Hong Kong," Lighting Research and Technology, vol. 32, no. 2, pp. 93-100, 2000.

[12] World Meteorological Organization (WMO), "Guide to meteorological instruments and methods of observation (sixth edition)," WMO-No.8, WMO, Geneva, Switzerland, 1996.

[13] P. R. Tregenza, "Subdivision of the sky hemisphere for luminance measurements," Lighting Research and Technology, vol. 19, no. 1, pp. 13-14, 1987.

[14] P. R. Tregenza and S. Sharples, New Daylight Algorithm, University of Sheffield, Sheffield, UK, 1995.

[15] B. A. LeBaron, J. J. Michalsky, and R. Perez, "A simple procedure for correcting shadow band data for all sky conditions," Solar Energy, vol. 44, no. 5, pp. 249-256, 1990.

[16] CIE Division 3 Committee, "Guide to recommended practice of daylight measurement," Tech. Rep. CIE 108-1994, Commission Internationale de l'Eclairage, Vienna, Austria, 1994.

[17] D. H. W. Li, G. H. W. Cheung, and J. C. Lam, "Analysis of the operational performance and efficiency characteristic for photovoltaic system in Hong Kong," Energy Conversion and Management, vol. 46, no. 7-8, pp. 1107-1118, 2005.

[18] A. Balouktsis, T. D. Karapantsios, K. Anastasiou, D. Paschaloudis, A. Bezergiannidou, and N. Bilalis, "Sizing stand-alone photovoltaic systems," International Journal of Photoenergy, vol. 2006, Article ID 73650, 8 pages, 2006.

[19] S. H. Yoo, E. T. Lee, and J. K. Lee, "Building integrated photovoltaics: a Korean case study," Solar Energy, vol. 64, no. 4, pp. 151-161, 1998.

[20] T. Muneer, "Perez slope radiation and illuminance model: evaluation against Japanese data," Lighting Research and Technology, vol. 29, no. 2, pp. 83-87, 1997.

[21] D. H. W. Li and G. H. W. Cheung, "Study of models for predicting the diffuse irradiance on inclined surfaces," Applied Energy, vol. 81, no. 2, pp. 170-186, 2005.

[22] Chartered Institution of Building Services Engineers (CIBSE), "CIBSE Guide A2," Chartered Institution of Building Services Engineers, London, UK, 1982.

[23] D. Prasad and M. Snow, Eds., Designing with Solar Power: A Source Book for Building Integrated Photovoltaics (BIPV), Images Publishing, Melbourne, Australia, 2005.

[24] J. A. Duffie and W. A. Beckman, Solar Engineering of Thermal Processes, John Wiley \& Sons, New York, NY, USA, 1991. 
[25] A. Balouktsis, T. D. Karapantsios, K. Anastasiou, A. Antoniadis, and I. Balouktsis, "Load matching in a directcoupled photovoltaic system-application to Thevenin's equivalent loads," International Journal of Photoenergy, vol. 2006, Article ID 27274, 7 pages, 2006.

[26] D. H. W. Li, J. C. Lam, and C. C. S. Lau, "A study of solar radiation daylight illuminance and sky luminance data measurements for Hong Kong," Architectural Science Review, vol. 45, no. 1, pp. 21-30, 2002.

[27] W. Durisch, D. Tille, A. Wörz, and W. Plapp, "Characterisation of photovoltaic generators," Applied Energy, vol. 65, no. 1-4, pp. 273-284, 2000.

[28] S. A. Kalogirou, "Use of TRNSYS for modelling and simulation of a hybrid PV-thermal solar system for Cyprus," Renewable Energy, vol. 23, no. 2, pp. 247-260, 2001.

[29] J. D. Mondol, Y. G. Yohanis, M. Smyth, and B. Norton, "Longterm validated simulation of a building integrated photovoltaic system," Solar Energy, vol. 78, no. 2, pp. 163-176, 2005.

[30] J. C. Lam, C. L. Tsang, and D. H. W. Li, "Long term ambient temperature analysis and energy use implications in Hong Kong," Energy Conversion and Management, vol. 45, no. 3, pp. 315-327, 2004.

[31] A. Fernández-Infantes, J. Contreras, and J. L. Bernal-Agustín, "Design of grid connected PV systems considering electrical, economical and environmental aspects: a practical case," Renewable Energy, vol. 31, no. 13, pp. 2042-2062, 2006.

[32] T. Muneer, S. Younes, N. Lambert, and J. Kubie, "Life cycle assessment of a medium-sized photovoltaic facility at a high latitude location," Proceedings of the Institution of Mechanical Engineers Part A, vol. 220, no. 6, pp. 517-524, 2006. 


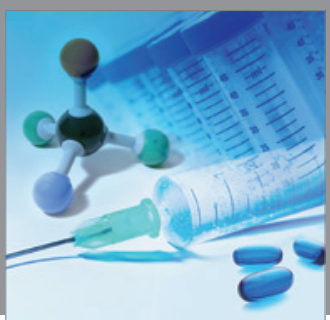

International Journal of

Medicinal Chemistry

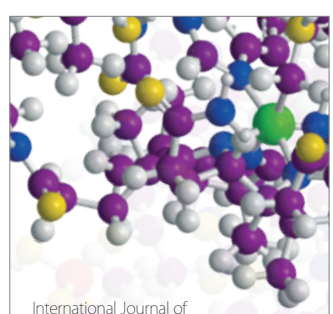

Carbohydrate Chemistry

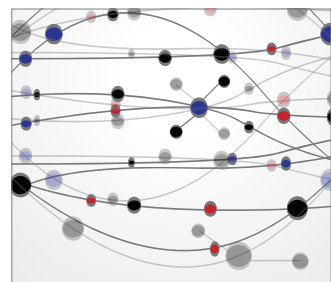

The Scientific World Journal
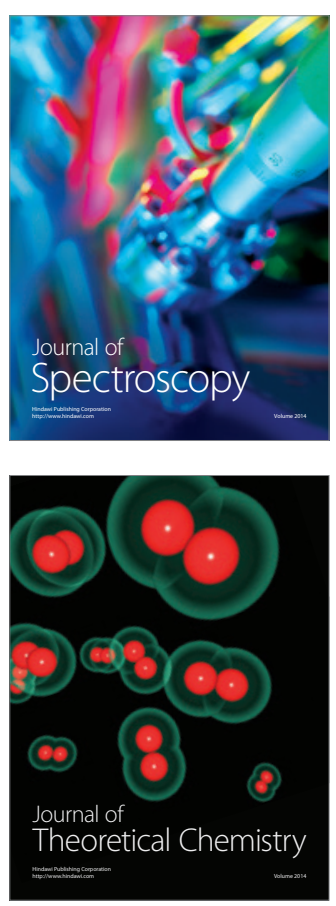
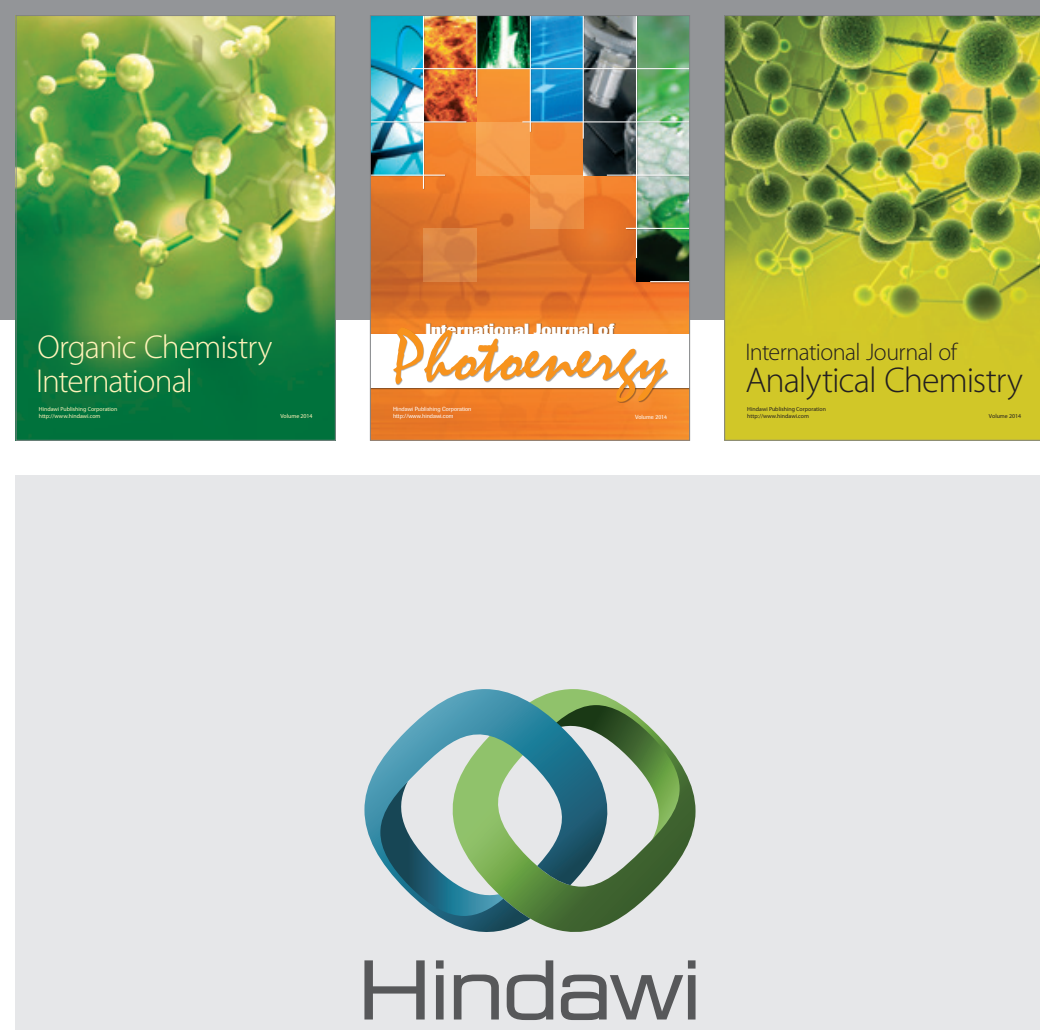

Submit your manuscripts at

http://www.hindawi.com
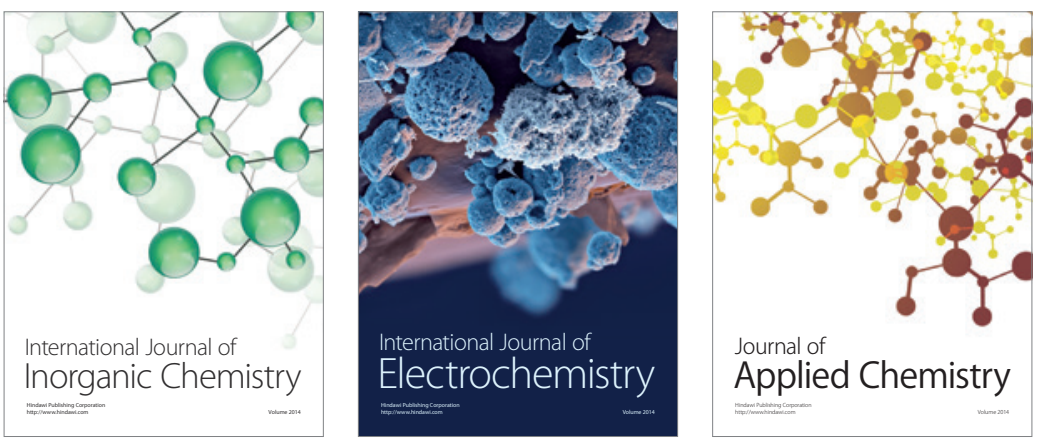

Journal of

Applied Chemistry
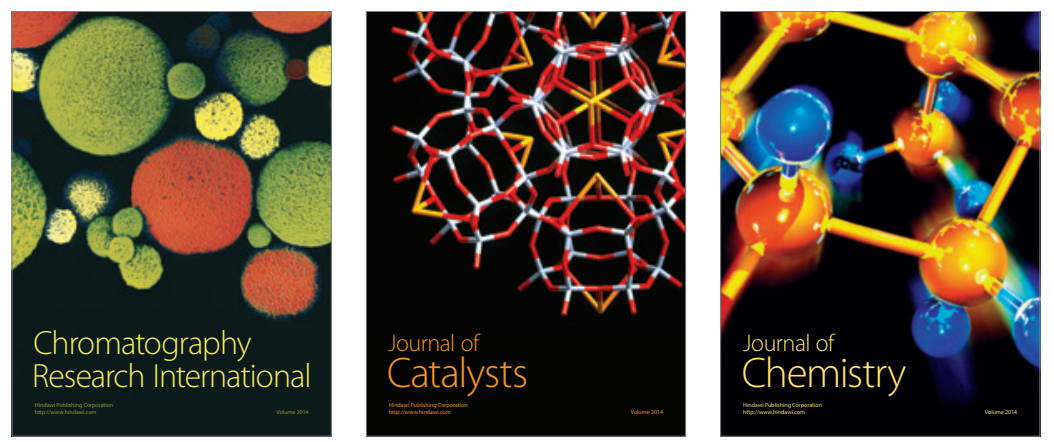
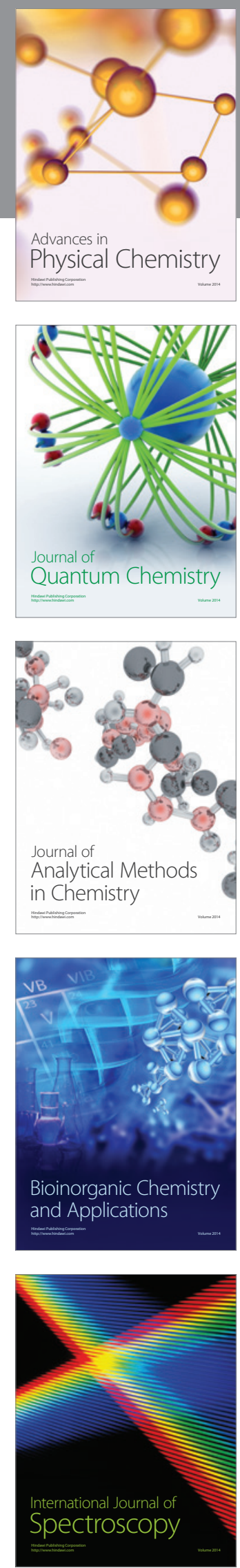